\title{
PENERAPAN MODEL MULTIPLE INTELLIGENCES UNTUK MENINGKATKAN HASIL BELAJAR SBdP TEMA 7 SUBTEMA 2 PADA SISWA KELAS IV SDN 3 SOBAYAN TAHUN AJARAN 2019/2020
}

\author{
Karenina Shalshal Agsari ${ }^{1}$, Rokhmaniyah ${ }^{2}$, Muh. Chamdani ${ }^{3}$ \\ Universitas Sebelas Maret \\ shalshalkarenina@gmail.com
}

\section{Article History}

accepted 01/10/2020

approved 01/11/2020

published 01/12/2020

\begin{abstract}
The study aimed to improve art and culture learning outcomes of the theme the beauty of diversity in my country'. It was collaborative classroom action research conducted in three cycles. The subjects were fourth grade students of SDN 3 Sobayan in academic year of 2019/2020. The data collection techniques were non-tests and tests. The data validity used source triangulation and method triangulation. The data analysis consisted of quantitative data and qualitative data. The results showed that the application of multiple intelligences model improved art and culture learning outcomes of theme 7 subtheme 2 to fourth grade students of SDN 3 Sobayan in academic year of 2019/2020. The student mastery learnings in the first cycle were $56 \%$ and $72 \%$. The second and third cycle could not be done because of covid-19 pandemic.
\end{abstract}

Keywords: multiple intelligences model, learning outcomes, art and culture lesson

\section{Abstrak}

Penelitian ini bertujuan untuk meningkatkan hasil belajar SBdP tema indahnya keberagaman di negeriku dengan metode penelitian tindakan kelas kolaboratif yang dilaksanakan dalam tiga siklus. Subjek penelitian adalah siswa kelas IV SDN 3 Sobayan tahun ajaran 2019/2020. Teknik dalam pengumpulan data terdiri nontes dan tes. Validitas data diuji menggunakan strategi triangulasi sumber data dan metode. Analisis data terdiri dari data kuantitatif dan data kualitatif. Hasil penelitian menunjukkan bahwa penerapan model Multiple Intelligences dapat meningkatakan hasil belajar SBdP tema 7 subtema 2 pada siswa kelas IV SDN 3 Sobayan tahun ajaran 2019/2020. Tingkat ketuntasan hasil belajar siswa di siklus I, yaitu $56 \%$ dan $72 \%$, dan untuk siklus II dan III tidak dilaksanakan dikarenakan Covid-19. Jadi, penerapan model Multiple Intelligences dapat meningkatkan pembelajaran SBdP pada tema 7 subtema 2 siswa kelas IV SDN 3 Sobayan tahun ajaran 2019/2020.

Kata kunci: Model Multiple Intelligences, Hasil Belajar, SBdP 


\section{PENDAHULUAN}

Pendidikan pada dasarnya merupakan suatu proses pengembangan potensi setiap individu. Tugas pendidik atau guru dalam hal ini adalah memfasilitasi siswa/peserta didik sebagai individu untuk dapat mengembangkan potensi yang dimiliki menjadi kompetensi yang sesuai dengan cita-citanya. Oleh karena itu, sebagai seorang pendidik kita harus tahu porsi pemahaman setiap siswa yang kita ajar dimana ada siswa hanya ahli dalam muatan pelajaran tertentu dan pelajaran yang lainnya tidak.

Tugas pendidik dalam hal ini adalah memfasilitasi peserta didik sebagai individu untuk dapat mengembangkan potensi yang dimiliki menjadi kompetensi yang sesuai dengan cita-citanya. Terutama siswa sekolah dasar yang masih memerlukan bimbingan dan pendampingan dalam belajar. Selain itu, sebagai pendidik harus memahami kecerdasan setiap siswanya agar saat memberikan pembelajaran di kelas berjalan lancar dan sesuai tujuan pembelajaran yang ingin dicapai seperti menggunakan model pembelajaran sebagai cara untuk mencapai tujuan pembelajaran.

Menurut Helmiati (2012:19) model pembelajaran adalah bentuk pembelajaran yang tergambar dari awal sampai akhir yang disajikan secara khas oleh guru. Dengan kata lain, model pembelajaran merupakan bungkus atau bingkai dari penerapan suatu pendekatan, metode, strategi, dan teknik pembelajaran. Model pembelajaran sangat berpengaruh dalam suatu pembelajaran karena suatu model pembelajaran dapat menggali potensi yang dimiliki oleh peserta didik dengan melihat dari intelegensi yang dimiliki oleh peserta didik.

Menurut Edward Thorndike (Sobur,2010) Intelegensi adalah kemampuan individu untuk memberikan respons yang tepat (baik) terhadap stimulasi yang diterimanya, sedangkan menurut William Stern (Sobur,2010) Intelegensi merupakan kapasitas atau kecakapan umum pada individu secara sadar untuk menyesuaikan pikirannya pada situasi yang dihadapinya. Jadi, dapat disimpulkan bahwa intelegensi adalah kemampuan individu secara sadar melalui situasi yang merangsang stimulus (respon) yang diterimanya.

Berdasarkan observasi yang telah dilakukan pada hari Sabtu tanggal 23 November 2019, proses pembelajaran kelas IV di SDN 3 Sobayan guru masih menggunakan model pembelajaran ekspositori dimana pembelajaran berusat pada guru sehingga siswa menjadi pasif di kelas walaupun kurikulum yang digunakan sudah kurikulum 2013. Dikarenakan anak lebih paham dengan materi yang diajarkan oleh guru dengan model ekspositori. Setelah melakukan wawancara dengan guru didapatkan kesimpulan bahwa peserta didik lebih tertarik muatan pelajaran SBdP berupa praktikum sehingga saat diberikan teori peserta didik cenderung mengobrol dan mengganggu temannya. Jadi, hal ini berpengaruh pada saat proses pembelajaran berlangsung dan hasil belajar peserta didik.

Pada hasil Ulangan Tengah Semester (UTS) siswa kelas IV di SDN 3 Sobayan pada semester 1 tahun ajaran 2019/2020 diperoleh rata-rata kelas 75,12 dari 25 siswa dengan $44 \%$ atau sebanyak 11 siswa yang belum mencapai KKM dan $56 \%$ atau sebanyak 14 siswa sudah mencapai KKM $(K K M=75)$. Nilai tertinggi adalah 90 dan nilai terendah 68 .

Jadi, pada hasil wawancara dan observasi yang dilakukan dapat dilihat bahwa perlu adanya upaya untuk meningkatkan hasil belajar peserta didik. Penelitian tindakan kelas ini dilaksanakan melalui kerjasama dengan guru kelas IV di SDN 3 Sobayan dengan judul "Penerapan Model Multiple Intelligences untuk Meningkatkan Hasil Belajar SBdP Tema 7 Subtema 2 Pada Siswa Kelas IV SDN 3 
Sobayan Tahun Ajaran 2019/2020"

Berdasarkan latar belakang masalah yang diuraikan, maka rumusan masalah dari penelitian ini adalah: (1) Bagaimana langkah-langkah penerapan model Multiple Intelligences untuk meningkatkan hasil belajar tentang SBdP tema 7 subtema 2 pada siswa kelas IV SDN 3 Sobayan tahun ajaran 2019/2020?; (2) Bagaimana penerapan model Multiple Intelligences untuk meningkatkan hasil belajar tentang SBdP tema 7 subtema 2 pada siswa kelas IV SDN 3 Sobayan tahun ajaran 2019/2020?; (3) Apa kendala dan solusi pada penerapan model Multiple Intelligences untuk meningkatkan hasil belajar tentang SBdP tema 7 subtema 2 pada siswa kelas IV SDN 3 Sobayan tahun ajaran 2019/2020?

Oleh karena itu, tujuan penelitian ini adalah: mendeskripsikan langkahlangkah ; meningkatkan hasil belajar; dan menemukan kendala dan solusi penerapan model Multiple Intellegences untuk meningkatkan hasil belajar SBdP tema 7 subtema 2 pada siswa kelas IV SDN 3 Sobayan tahun ajaran 2019/2020.

\section{METODE}

Jenis Penelitian yang akan dilaksanakan ini adalah penelitian tindakan kelas. Menurut Hopkins (Muslich, 2013:8) Penelitian Tindakan Kelas (PTK) adalah suatu bentuk kajian yang bersifat reflektif, yang dilakukan oleh pelaku tindakan untuk meningkatkan kemantapan rasional dan tindakan-tindakannya dalam melaksanakan tugas dan memperdalam pemahaman terhadap kondisi dalam praktik pembelajaran.

Subjek dalam penelitian ini adalah siswa kelas IV SDN 3 Sobayan tahun ajaran 2019/2020. Data penelitian ini data kuantitatif berupa data hasil ulangan tengah semester (UTS) muatan pelajaran SBdP siswa kelas IV SDN 3 Sobayan yang diadakan pada pertengaha semester 1 tahun ajaran 2019/2020, sedangkan data kualitatif berupa observasi wawancara terhadap guru dan siswa mengenai pembelajaran SBdP dengan menerapkan model Multiple Intelligences. Teknik pengumpulan data menggunakan teknik tes dan non-tes. Uji validitas data menggunakan teknik triangulasi akan menggunakan empat cara dalam pengumpulan data, yaitu teknik tes, observasi, wawancara, dan dokumentasi. Analisis data meliputi reduksi data, penyajian data, dan penarikan kesimpulan. Indikator yang menjadi pedoman keberhasilan adalah respon guru dan siswa terhadap model Multiple Intelligences tentang indahnya keberagaman di negeriku, dan peningkatan pembelajaran SBdP (proses, sikap, dan hasil belajar) tentang indahnya keberagaman di negeriku dengan $\mathrm{KKM}=75$.

\section{HASIL DAN PEMBAHASAN}

Penelitian ini dilaksanakan dengan menerapkan lima langkah model Multiple Intelligences yang meliputi: (1) Alpha Zone, (2) Warmer, (3)Pre-teach, (4) Scene setting, (5) Multile strategy. Langkah-langkah yang digunakan peneliti mengacu pada langkah model Multiple Intelligences yang dikemukakan oleh John F. Herbert (Salamah, 2016:37) dan Chatib ( Salamah, 2016:37).

Hasil pengamatan terhadap guru maupun siswa dalam penerapan model Multiple Intelligences selalu mengalami peningkatan pada setiap pertemuan walaupun belum mencapai indikator pencapaian yang ditargetkan. 
Tabel 1 Perbandingan Persentase Melalui Teknik Observasi dan Wawancara Terhadap Guru dan Siswa pada Siklus I Pertemuan 1 dan 2

\begin{tabular}{ccccc}
\hline Pertemuan Ke- & \multicolumn{2}{c}{ Observasi } & \multicolumn{2}{c|}{ Wawancara } \\
\cline { 2 - 5 } & Guru (\%) & Siswa (\%) & Guru (\%) & Siswa (\%) \\
\hline 1 & 70,28 & 69,67 & 52,67 & 48,22 \\
2 & 74,64 & 71,39 & 69,67 & 70,67 \\
\hline
\end{tabular}

Berdasarkan tabel di atas, diketahui hasil observasi terhadap guru dan siswa pada siklus I pertemuan 1 dan 2 mengalami peningkatan pada setiap pertemuan. Hal tersebut juga didukung dengan hasil wawancara yang dilakukan oleh peneliti terhadap guru dan siswa sehingga dapat dikatakan langkah penerapan model Multiple Intellgences pada guru dan siswa sudah dilaksanakan dengan baik walaupun hanya dilaksanakan 1 siklus diakibatkan Covid-19 sehingga penelitan belum selesai dilaksanakan hingga siklus III dan memperoleh data yang valid.

Tabel 2 Analisis Hasil Belajar SBdP Siklus I

\begin{tabular}{|l|l|c|c|c|c|c|}
\hline \multirow{2}{*}{$\begin{array}{c}\text { No } \\
.\end{array}$} & \multirow{2}{*}{ Rentang } & \multicolumn{2}{|c|}{ Frekuensi } & \multicolumn{2}{|c|}{ Persentase(\%) } & \multirow{2}{*}{ Keterangan } \\
\cline { 3 - 6 } & & Pert 1 & Pert 2 & Pert 1 & Pert 2 & \\
\hline 1. & $\leq 54$ & 1 & 0 & 4 & 0 & Belum Tuntas \\
\hline 2. & $55-59$ & 2 & 0 & 8 & 0 & Belum Tuntas \\
\hline 3. & $60-64$ & 3 & 3 & 12 & 12 & Belum Tuntas \\
\hline 4. & $65-69$ & 1 & 1 & 4 & 4 & Belum Tuntas \\
\hline 5. & $70-74$ & 3 & 3 & 12 & 12 & Belum Tuntas \\
\hline 6. & $75-79$ & 2 & 4 & 8 & 16 & Tuntas \\
\hline 7. & $80-84$ & 5 & 11 & 20 & 44 & Tuntas \\
\hline 8. & $\geq 85$ & 8 & 3 & 32 & 12 & Tuntas \\
\hline Jumlah & 25 & 25 & 100 & 100 & - \\
\hline Rata-rata & 76,52 & 77,68 & - & - & - \\
\hline Nilai Tertinggi & 93 & 90 & - & - & - \\
\hline Nilai Terendah & 53 & 60 & - & - & - \\
\hline \multicolumn{2}{|l|}{ Tuntas } & 15 & 18 & 56 & 72 & - \\
\hline \multicolumn{2}{|l|}{ Belum Tuntas } & 10 & 7 & 44 & 28 & - \\
\hline
\end{tabular}

Berdasarkan analisis terhadap peningkatan pembelajaran pada siklus I pertemuan 1 dan 2, maka dapat disimpulkan bahwa ketuntasan hasil belajar SBdP belum mencapai target indikator kinerja yaitu 85\% dengan KKM sebesar 75 . Oleh karena itu, perlu melakukan perbaikan dan pemantapan pada penelitian selanjutnya yaitu pada siklus II dan III dalam menerapkan model Multiple Intelligences, sehingga hasil belajar SBdP dapat meningkat serta indikator kinerja dan KKM yang ditargetkan dapat tercapai. Namun, penelitian berhenti pada siklus I pertemuan 2 dikarenakan Covid-19.

Pada pelaksanaan pembelajaran yang dilakukan dengan menerapkan model Multiple Intelligences tidak terlepas dari kendala yang dihadap, akan tetapi peneliti dan guru telah berupaya untuk mengatasi kendala tersebut. Kendala selama penelitian siklus I pertemuan 1 dan 2 yang dihadapi oleh penelitian, yaitu: (a) siswa masih malu dan ragu dalam bertanya dan menjawab pertanyaan dari guru; (b) siswa masih ada yang berbicara dan bermain saat proses diskusi; (c) siswa masih ada yang malu untuk mempresentasikan dan menyampaikan hasil 
diskusi ke depan kelas; (d) guru masih belum bisa mengendalikan siswa yang berbicara di kelas saat proses diskusi.Kendala tersebut sesuai dengan yang diungkapkan oleh Firdaus (2012) bahwa proses pembelajaran dengan menggunakan model Multiple Intelligences masih belum optimal dimana siswa masih kurang keberanian untuk mengeluarkan pendapat pada saat aktivitas tanya jawab dengan guru, sehingga kreativitas berpendapat siswa pun belum muncul dengan baik. Selain itu, kendala tersebut sesuai yang diungkapkan oleh Hamzah (2014) bahwa siswa akan lebih mudah memahami pelajaran jika materinya disajikan sesuai dengan inteligensi yang menonjol dalam diri siswa.

Adapun solusi dari permasalahan tersebut yaitu: (a) guru memberikan hadiah kepada siswa yang bisa menjawab dan bertanya agar sisa termotivasi; (b) guru memberi teguran atau sanksi yang tegas kepada siswa yang berbicara saat proses diskusi; (c) guru menstimulasi siswa dengan pernyataan-pernyataan atau pertanyaan-pertanyaan yang membuat siswa terpancing untuk berbicara; (d) guru menggunakan kembali strategi dan membagi siswa dalam bentuk kelompok yang sama.

Kelebihan menerapkan model Multiple Intelligences yakni, menyenangkan, dapat mengetahui intelegensi yang menonjol pada diri anak, dan memudahkan siswa dalam memahami pembelajaran. Hal ini sesuai dengan kelebihan model Multiple Intelligences yang diungkapkan oleh Amir (2013), yaitu: (1) Guru dapat menggunakan kerangka Multiple Intelligences dalam melaksanakan proses pengajaran secara luas; (2) Dengan menggunakan Multiple Intelligences anda dapat menyediakan kesempatan bagi siswa untuk belajar sesuai dengan kebutuhan, minat, dan talentanya; (3) Peran serta orang tua dan masyarakat akan semakin meningkat di dalam mendukung proses belajar mengajar; (4) Siswa akan mampu menunjukkan dan berbagi tentang kelebihan yang dimilikinya; (5) Pada saat Anda "mengajar untuk memahami" ,siswa akan mendapatkan pengalaman belajar yang positif dan meningkatkan kemampuan untuk mencari solusi dalam memecahkan persoalan yang dihadapinya. Selain itu, kelebihan sesuai dengan yang diungkapkan Firdaus (2012), yaitu: (1) Respon dalam suatu masalah; (2) Fleksibel dalam berendapat; (3) Kritis dalam permasalahan; (4) Mengungkapkan pendapat dengan kalimat lengkap.

\section{SIMPULAN}

Berdasarkan rumusan masalah, hasil penelitian, dan pembahasan dalam penelitian dapat disimpulkan peningkatan hasil belajar SBdP tema 7 subtema 2 dengan model Multiple Intelligences kelas IV SDN 3 Sobayan tahun ajaran 2019/2020 dilaksanakan dengan langkah-langkah: (1) Tahap pertama Alpha Zone, (2) Warmer, (3) Pre-Teach, (4) Scene Setting,(5) Multiple Strategy. Penerapan model Multiplelntelligences dapat meningkatakan hasil belajar SBdP tema 7 subtema 2 pada kelas IV SDN 3 Sobayan tahun ajaran 2019/2020. Hal ini terbukti peningkatan persentase ketuntasan kinerja $(\mathrm{KKM}=75)$ pada siklus I pertemuan 1 sebesar $56 \%$, sedangkan siklus I pertemuan 2 sebesar $72 \%$, dan rata-rata siklus I pertemuan 1 dan 2 sebesar 64\%, siklus II dan III tidak dilaksanakan dikarenakan Covid-19. Kendala dan solusi penerapan model Multiple Intelligences dalam meningkatkan hasil belajar SBdP tema 7 subtema 2 pada kelas IV SDN 3 Sobayan tahun ajaran 2019/2020, yaitu: siswa masih malu untuk bertanya kepada guru tentang materi yang dipelajari. Solusi dari kendala tersebut yaitu guru memberi pernyataan atau pertanyaan untuk memancing siswa 
bertanya.

Berkaitan dengan hasil penelitian yang telah dicapai, peneliti mengajukan saran sebagai berikut: (1) Guru lebih memahami intelegensi siswa dalam bidangnya, (2) Guru menggunakan model Multiple Intelligences pada tema lain atau muatan pembelajaran lainnya, (3) Guru menggunakan strategi pembelajaran yang membuat siswa paham, (4) Guru membimbing siswa dalam menggunakan media pembelajaran dengan bijak, (5) Guru membimbing siswa menerapkan budaya literasi.

\section{DAFTAR PUSTAKA}

Amir, Almira. 2013. Pembelajaran Matematika Dengan Menggunakan Kecerdasan Majemuk (Multiple Intelligences). Logaritma Vol. I No. 1 Januari 2013

Firdaus, F.M. 2012. Model Multiple Intelligences Untuk Meningkatkan Kreativitas Berpendapat Siswa Dalam Pembelajaran IPS. Edu Humanira, Vol. 4 No. 1 , Januari 2012 E-ISSN 2579-5457 P-ISSN 2085-1243.

Hamzah, A. 2014. Teori Multiple Intelligences Dan Implikasinya Terhadap Pengelolaan Pembelajaran. Tadris Vol. 4 No. 2 tahun 2014.

Helmiati. 2012. Model Pembelajaran. Yogyakarta: Aswaja Presindo. https://docplayer.info/39661823-Model-pembelajaran-dr-hi-helmiati-mag.html

Muslich, M. 2013, Melaksanakan PTK (Penelitian Tindakan Kelas) Itu Mudah Classroom Action Research. Jakarta: PT. Bumi Aksara

Salamah, U. 2016. Pengaruh Penerapan Strategi Pembelajaran Berbasis Multiple Intelligences Terhadap Hasil Belajar IPS Siswa Kelas V SD Negeri 01 Rajabasa Bandarlampung. http://digilib.unila.ac.id

Sobur, A. 2010. Psikologi Umum. Bandung: Pustaka Setia 